\title{
Analysis on the influence factors of Bitcoin's price based on VEC model
}

\author{
Yechen Zhu ${ }^{1 *}$, David Dickinson ${ }^{2}$ and Jianjun $\mathrm{Li}^{1}$
}

\footnotetext{
* Correspondence: yczhu@163.com

${ }^{1}$ School of Finance, Central University of Finance and Economics, Beijing 100081, China Full list of author information is available at the end of the article
}

\begin{abstract}
Background: Bitcoin, the most innovate digital currency as of now, created since 2008, even through experienced its ups and downs, still keeps drawing attentions to all parts of society. It relies on peer-to-peer network, achieved decentralization, anonymous and transparent. As the most representative digital currency, people curious to study how Bitcoin' price changes in the past.

Methods: In this paper, we use monthly data from 2011 to 2016 to build a VEC model to exam how economic factors such as Custom price index, US dollar index, Dow jones industry average, Federal Funds Rate and gold price influence Bitcoin price.
\end{abstract}

Result: From empirical analysis we find that all these variables do have a long-term influence. US dollar index is the biggest influence on Bitcoin price while gold price influence the least.

Conclusion: From our result, we conclude that for now Bitcoin can be treated as a speculative asset, however, it is far from being a proper credit currency.

Keywords: Bitcoin price, Gold price, US dollar index, VEC model

\section{Background}

Bitcoin, the most innovate digital currency as of now, created since 2008, even though experienced its ups and downs, still keeps drawing attentions to all parts of society. It first appear in a paper written by Nakamoto (2008), this paper described Bitcoin as a pure peer-to-peer electronic cash, which achieves decentralization, anonymous and transparent. The genesis block was mined with a total number of 50 BTC in 2009. In May 2010, a Florida programmer use 10,000 BTC to purchase a pizza worth US $\$ 25$, this is first Bitcoin transaction in real world. From 2011 to 2013, in only 3 years, Bitcoin price rise one hundred thousand times and goes above $\$ 1000$ in Nov. 2013. The turn down start since one of the biggest Bitcoin company Mt. Gox's bankruptcy, market start lose faith in Bitcoin and Bitcoin price suffer a big drop from then. But it seems that it will always return to its trend when the impact is over. In the year of 2016, Bitcoin's price have changed significantly from $\$ 360$ to $\$ 766.62$ and still have chance to go higher at the end of this year (Fig. 1). No need to say how Bitcoin price changed since 2011 when it first came to people's attention. This observation can lead to many questions worth to study on. Such as what influence Bitcoin price? What is the relationship between Bitcoin and other economy indicator? Is there any connection between Bitcoin price and stock market index? All these questions are remain unsolved.

(C) The Author(s). 2017 Open Access This article is distributed under the terms of the Creative Commons Attribution 4.0 International License (http://creativecommons.org/licenses/by/4.0/), which permits unrestricted use, distribution, and reproduction in any medium, provided you give appropriate credit to the original author(s) and the source, provide a link to the Creative Commons license, and indicate if changes were made. 


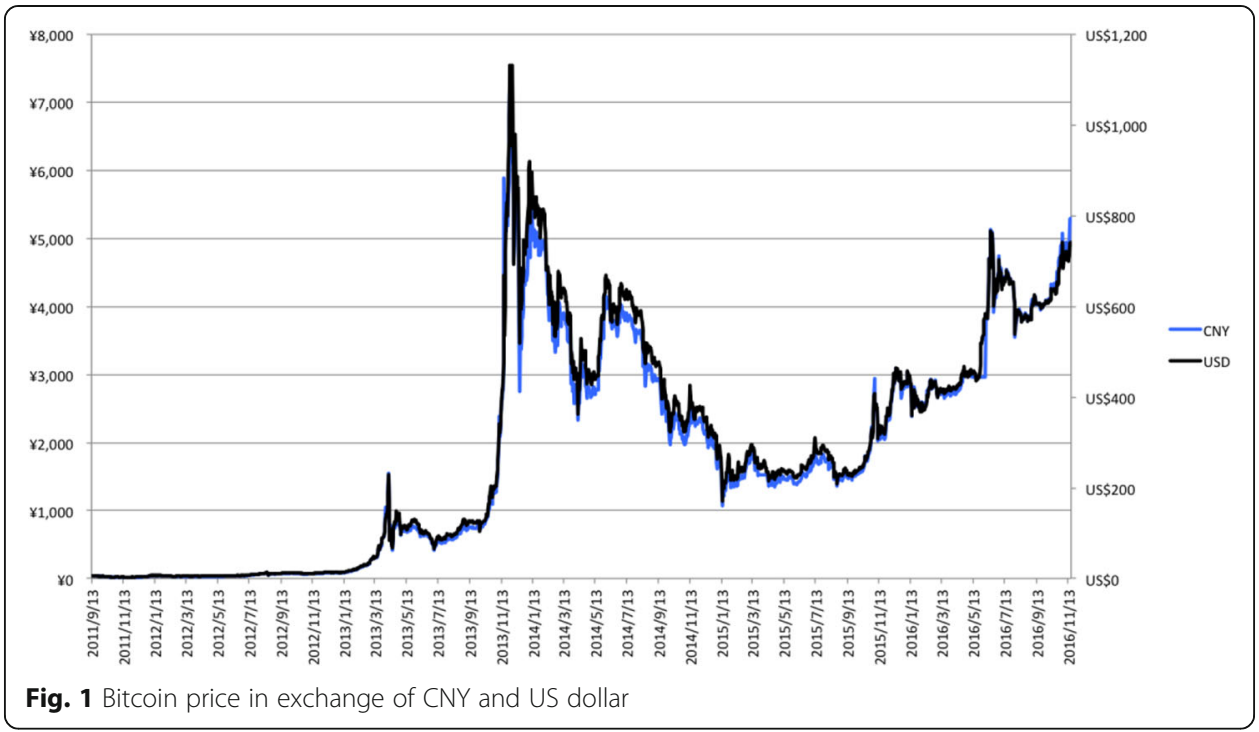

Until today, only a few country explicitly allowed Bitcoin's use and trade, most country have difficulties to classify Bitcoin, and some country, such as China have banned the use of Bitcoin. Although most countries in the world holds different policy against Bitcoin, it certainly did not slow down Bitcoin's development. We can see this from the Fig. 1, Bitcoin price has the same tendency in exchange of CNY and UD dollar.

However, as Bitcoin booming in the market, there is still lack of a definition in the academic world to clarify whether Bitcoin is a currency or simply an investment. Most scholar support that Bitcion is only a commodity at this point, a few have the faith that it will become a real currency eventually. Šurda (2014) holds the opinion that the trust between economy participants make sure the Bitcoin system run smoothly, however, Bitcoin has no intrinsic value, it's value only depends on market strength and the belief from users. From that point of view, Bitcoin is a commodity rather than a currency. Yermack (2013) holds the same opinion, which is Bitcoin appears to behave more like a speculative investment than a currency. In his paper he point out that, on the one hand, Bitcion's exchange rate has no relativity to the main currencies in the world, makes it's hard for Bitcoin holders to make risk management and to hedge to other currency. On the other hand, Bitcoin make it's hard to count in banking system with deposit insurance. Bergstra and Weijland (2014) consider Bitcoin as a Money-like Informational Commodity (MLIC). Chinese scholar Jia (2013) analyses that Bitcoin can provide a majority function as a currency, but not yet a real currency. Wu and Pandey (2014) analysis the value of Bitcoin in enhancing the efficiency of an investor's portfolio, they suggest that Bitcoin may be less useful as a currency; it can enhance the efficiency of an investor's portfolio.

"What we want from a monetary system isn't to make people holding money rich; we want it to facilitate transactions and make the economy as a whole rich." Paul R. Krugman (2011) said. He refer Bitcoin as "Golden block chain", but he also concerned that, fixed supply will push Bitcoin price to a higher place, causing hoarding, deflation and economic depression. Therefore, analyses how Bitcoin price influenced by economic factors can be very helpful to understanding Bitcoin better. In this paper, we decide to analysis what factors influence Bitcoin price. People always compare Bitcoin to Gold as they both have 
limited number and can used as a purchase method. We choose some factors which may influence gold price and add gold price in our model so that we could analysis whether gold price have influence on Bitcoin's price.

The remainder of this paper is organized as follows: Related work section briefly explains the key aspects of Bitcoin necessary in the course of this paper and additionally sums up related work. Methods section describes our methodology and data when analyzing Bitcoin's prices. In Empirical analysis section is empirical analysis using VEC model. In Analysis on the influence factors of Bitcoin's price section we present and discuss our results and gives some hints for future research.

\section{Related work}

Since Bitcoin appears, plenty of scholars have study on it from different perspective. Grinberg (2011) compared Bitcoin to its competition, leads to the conclusion that it is a great alternative currency for gold bugs who prefer to hold currencies fully backed by commodities. However whether Bitcoin is a security will have to await an SEC or court interpretation for certainty. Barber et al. (2012) performed an in-depth investigation to understand what made Bitcoin so successful, while decades of research on cryptographic e-cash has not lead to a large-scale deployment. They draw the conclusion that the core design of Bitcoin could support a robust decentralized currency if done right. Bergstra and Weijland (2014) compared several other candidate type for a preferred base type for Bitcoin and classified Bitcoin as a system of type money-like informational commodity (MLIC). Cusumano (2014) currently see Bitcoins less like a currency and more like a computer- generated commodity. Wu and Pandey (2014) examined Bitcoin's role as a currency and it's efficiency as a investment asset. They suggested that Bitcoin is less useful as a currency but it can play an important role in enhancing the efficiency of an investor's portfolio. Yelowitz and Wilson (2015) studied Bitcoin from a different angle, they analyzed characteristics of Bitcoin users and find that computer programming and illegal activity search terms are positively correlated with Bitcoin interest, while Libertarian and investment terms are not. Cheah and Fry (2015) analyzed Bitcoin from the perspective of speculative-bubble, empirical results showed that Bitcoin prices are prone to speculative bubbles and the fundamental value of Bitcoin is zero. Dyhrberg (2015a, b; 2016) applied the asymmetric GARCH methodology used in studies of gold to explore the hedging capabilities. He find Bitcoin has some of the same hedging abilities as gold, and further more, it can be classified as something in between gold and the American dollar on a scale from pure medium of exchange advantages to pure store of value advantages.

Similar to Dyhrberg (2015a, b; 2016), in this paper, we attempted to analysis factors influencing Bitcoin price, using the factors that have a influence on gold price. We attempt to build a VEC model to accomplish such study. In's study, they used data from 2010 to 2014, they selected seven variables and use ARDL bounds testing method to analysis the long-run relationships among their variables, then they use VEC granger causality test to analysis the causal links between their variables. They reach the conclusion that Bitcoin is not stable in the long run and there's no sign it being a save haven. 


\section{Methods}

In order to decide variables that could have an influence on Bitcoin's price, we set gold price as an object of reference. Existing research shows that Dow Jones Industrial Average and all the financial assets' price are have a negative influence on gold price (Smith 2001; World gold council 2002) and macroeconomic variables such as GDP and inflation rate have on significant influence on the return of gold (Lawrence 2003). We select our variables based on these results to test how financial assets' price and macroeconomic influence on Bitcoin price, and since Bitcoin is constantly referring as digital gold, are these variables have the same effect on Bitcoin price as they did in gold price.

\section{The selection of variables}

In an attempt to analysis what factors influence Bitcoin price (BTC), we choose variables as follows: Consumer Price Index for All Urban Consumers: All Items (CPI), Dow Jones Industrial Average (DJIA), US dollor Index (USDI), Effective Federal Funds Rate (FFR), Gold Fixing Price 3:00 P.M. (London time) in London Bullion Market, based in U.S. Dollars (GP). We choose these variables because they are always been considered in gold price researches and we also want to find out the relationship between gold price and Bitcoin price.

\section{The source of data}

The time serial data collected from 09/2011-03/2016. The data of CPI, DJIA, FFR, USDI, GP are from Federal Reserve Bank of St. Louis ${ }^{1}$ and the data of BTC are from Bitcoin Charts. ${ }^{2}$ CPI is originally monthly data, we adjusted other data to monthly use the method of monthly average so that all the frequency of data can be matched. In order to eliminate heteroscedasticity of time series data, the logarithmic data were used for the empirical analysis. We also use seasonal adjustment to remove seasonal component. The statistical description of sample data is in Table 1.

\section{Empirical analysis method}

To analysis the long-term dynamic relationship between Bitcoin price and other variables in VAR model, we first make Augmented Dickey-Fuller (ADF) test unit root test for all the variables to examine their before building Vector Autoregressive (VAR) Model. Then we build VAR model and examine cointegration relationship among variables using Johansen test. Thirdly, we build Vector Error Correction (VEC) Model based on the VAR model and use Granger causality test to determine causal relationship between BTC and

Table 1 Statistical description of sample data

\begin{tabular}{lllllll}
\hline & LNBTC_SA & LNCPI_SA & LNDJIA_SA & LNFFR_SA & LNGP_SA & LNUSDI_SA \\
\hline Mean & 4.370483 & 5.454165 & 9.630293 & -2.144423 & 7.223755 & 4.661398 \\
Median & 5.377575 & 5.458934 & 9.675392 & -2.224956 & 7.172151 & 4.625312 \\
Maximum & 6.593415 & 5.473539 & 9.793074 & -0.985265 & 7.466386 & 4.823949 \\
Minimum & 0.945035 & 5.423173 & 9.337332 & -2.743558 & 6.987249 & 4.578563 \\
Std. Dev. & 1.848791 & 0.015853 & 0.137946 & 0.382711 & 0.155713 & 0.074511 \\
Observations & 55 & 55 & 55 & 55 & 55 & 55 \\
\hline
\end{tabular}


other variables. Finally, we use impulse response function and variance decomposition base on VEC model to find out the effects and contribution of shocks on the adjustment path of variables.

\section{Results and discussion}

In empirical analysis, we choose the vector autoregressive (VAR) model. VAR model is a general framework used to describe the dynamic interrelationship among stationary variables. We first run ADF test to test the model's stationarity. Then we build the VAR model and run Johansen cointegration test based on this primary model to test the long-term dynamic equilibrious relationship in this model. Follow up, we build a VEC model based on the VAR model to exam short run properties of the cointegrated series. The vector error correction (VEC) model is just a special case of the VAR for variables that are stationary in their differences. The VEC can also take into account any cointegrating relationships among the variables, which is why we choose this model in this study. Finally we read from the result of impulse response function and variance decomposition for more detailed information.

\section{ADF unit root test}

To avoid spurious regression, we first run ADF unit root test on the original data to test the stationarity. We use Eviews 9.0 on all the empirical analysis. ADF test results indicated lnbtc_sa, Incpi_sa, lndjia_sa, lnffr_sa, lnusdi_sa and lngp_sa are all non-stationarity but they all stationary after first difference, so that we can say they are integrated at the first order. The ADF test result is summarized in Table 2.

Because of all the variables are integrated, we can build VAR model to test their cointegration.

\section{VAR model and Johansen cointegration test}

To estimate the dynamic relationship between entire endogenous variables, VAR model utilizes regression analysis on lagged value of explained variables in the form of simultaneous equations (Sims 1980). Thus, VAR model has been utilized to explore the

Table 2 ADF test results

\begin{tabular}{lll}
\hline Variables & Prob. & Conclusion \\
\hline Inbtc_sa & 0.8674 & non-stationarity \\
dlnbtc_sa & 0.0019 & stationarity \\
Incpi_sa & 0.4761 & non-stationarity \\
dlncpi_sa & 0.0003 & stationarity \\
Indjia_sa & 0.9965 & non-stationarity \\
dlndjia_sa & 0.0000 & stationarity \\
Inffr_sa & 0.9369 & non-stationarity \\
dlnffr_sa & 0.0016 & stationarity \\
Inusdi_sa & 0.4866 & non-stationarity \\
dlnusdi_sa & 0.0042 & stationarity \\
Ingp_sa & 0.6042 & non-stationarity \\
dlngp_sa & 0.0000 & stationarity \\
\hline
\end{tabular}


relationship between financial sector development and economic development (Anwar et al., 2011; Ho and Odhiambo, 2013) and the relationship between equipment investment and economic growth (Herrerias, 2010). In our case, the smallest Akaike information criterion (AIC) and Schwarz information criterion (SC) value are not in the same lag order, the smallest AIC value is at lag 4 and the smallest SC value is at lag one. Because of $\mathrm{R}$-squared is a statistical measure of how close the data are to the fitted regression line, we choose lag 4 for our VAR model. ${ }^{3}$

Table 3 present the result of Johansen test, as we can see, there are four cointegration equations at the significance level of 0.05. Thus, we can draw a conclusion that there exists a long-term dynamic equilibrious relationship between Bitcoin price and other variables.

\section{Granger causality test}

Granger causality test can exam whether there exists causality between two variables. Table 4 presents the results of granger causality. As we can see, GP and USDI are the Granger-cause of Bitcoin price. CPI, DJIA and FFR are not Granger-cause of Bitcoin price.

\section{VEC model}

Now we know that there exists a long-term dynamic equilibrious relationship between Bitcoin price and other variables, we can now build a VEC model baced on the VAR model we have to exam short run properties of the cointegrated series. The model with Substituted Coefficients is as below:

Table 3 Johanson cointegration test results

\begin{tabular}{lllll}
\hline Unrestricted Cointegration Rank Test (Trace) & & & \\
\hline Hypothesized & & Trace & 0.05 & \\
No. of CE(s) & Eigenvalue & Statistic & Critical value & Prob. \\
\hline None $^{\text {a }}$ & 0.621571 & 147.7871 & 83.93712 & 0.0000 \\
At most 1 $^{\text {a }}$ & 0.520949 & 98.22902 & 60.06141 & 0.0000 \\
At most 2 $^{\text {a }}$ & 0.491372 & 60.69565 & 40.17493 & 0.0001 \\
At most 3 $^{\text {a }}$ & 0.276809 & 26.21774 & 24.27596 & 0.0281 \\
At most 4 & 0.116945 & 9.689530 & 12.32090 & 0.1327 \\
At most 5 & 0.063517 & 3.346801 & 4.129906 & 0.0798 \\
\hline
\end{tabular}

Trace test indicates 4 cointegrating eqn(s) at the 0.05 level

${ }^{a}$ denotes rejection of the hypothesis at the 0.05 level

${ }^{* *}$ MacKinnon-Haug-Michelis (1999) $p$-values

Table 4 Granger causality test results

\begin{tabular}{llll}
\hline Dependent variable: LNBTC_SA & & & \\
Excluded & Chi-sq & df & Prob. \\
\hline LNCPI_SA & 4.588062 & 4 & 0.3322 \\
LNDJIA_SA & 4.075893 & 4 & 0.3958 \\
LNFFR_SA & 5.923070 & 4 & 0.2050 \\
LNGP_SA & 13.31688 & 4 & 0.0098 \\
LNUSDI_SA & 13.26422 & 4 & 0.0101 \\
All & 21.62317 & 20 & 0.3613 \\
\hline
\end{tabular}




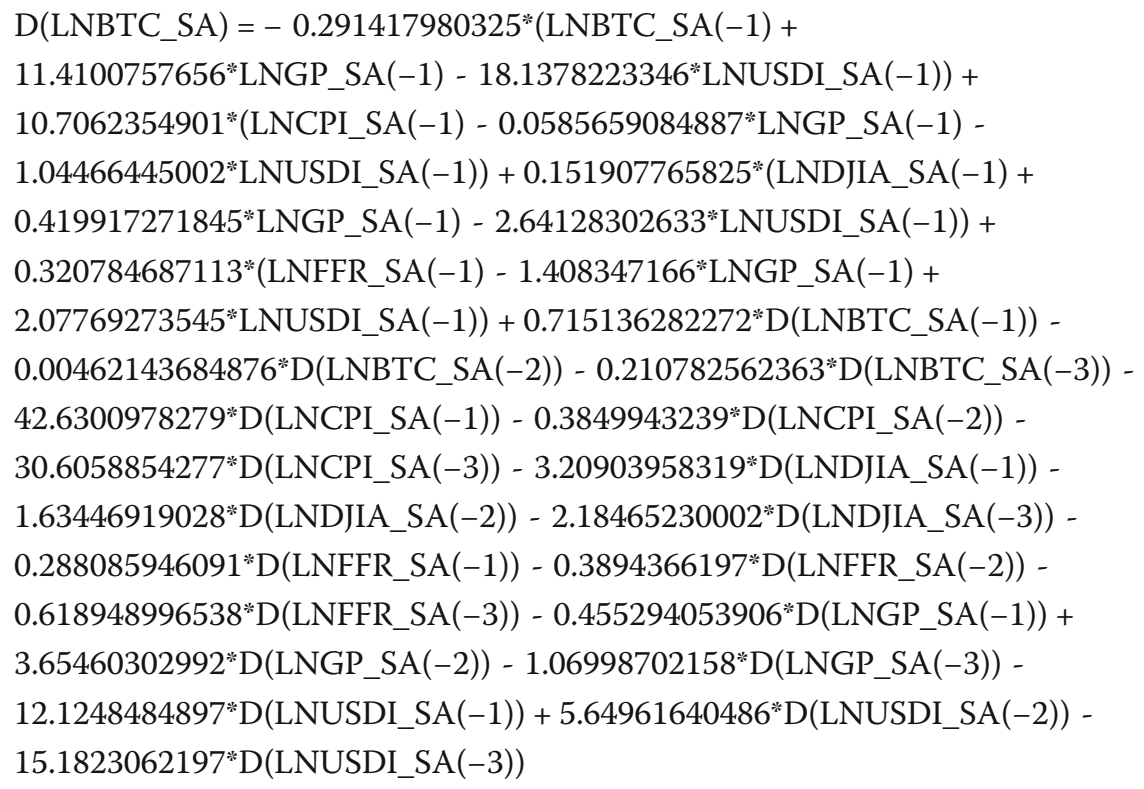

We test this equation and come to two conclusions:

First, the long run causality exists from CPI, DJIA, FFR, GP and USDI to BTC, which is -0.2914 .

Second, the short run causality exists from CPI, GP and USID to BTC.

Finally we test VEC stability condition, Fig. 2 is the AR roots graph, and all the spots are in the unit circle so the model is stable.

\section{Impulse response function}

To exam the impact of an endogenous variable on current and future value of other variables, impulse response function can generally be used to analyse the dynamic effect of one standard deviation of the random interference on the overall system in

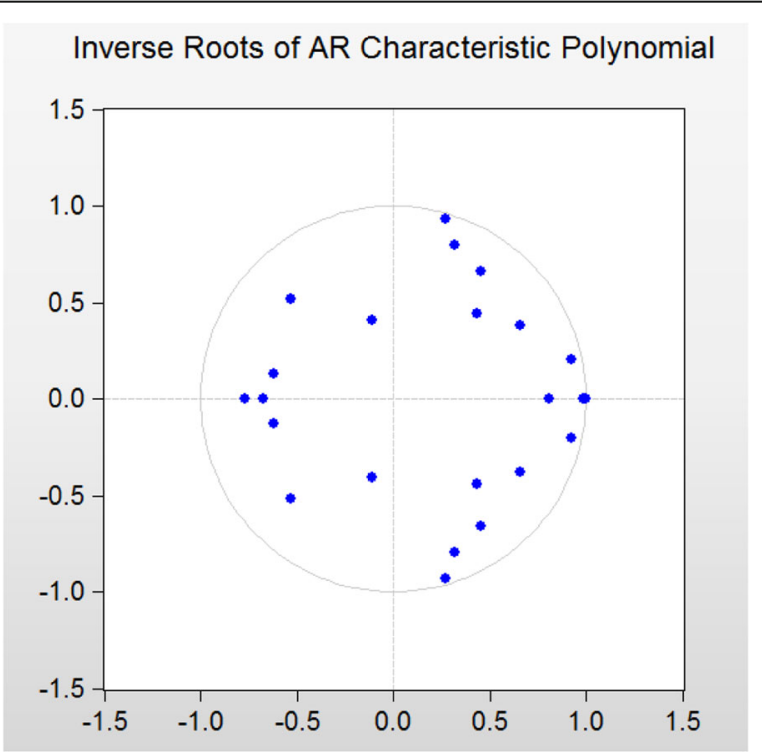

Fig. 2 AR roots graph 
VAR/VEC model. We adopt impulse response function to analysis the dynamic relationship between BTC and other variables. Figure 3 shows the results of impulse response function.

Figure 3 shows that the impulse response of BTC to all the other variables is zero in the first period. After the first period, the impulse response of BTC to DJIA, FFR and USDI are increasingly negative. The impulse response of BTC to CPI and GP are negative at first, and become positive at period 10 and period 19.

We calculate the average impulse response to BTC in 50 period, the results are present in Table 5. In average, USDI has the biggest influence on BTC, which is a negative influence. Successively are DJIA, FFR, CPI. GP has the weakest influence on BTC in average.

\section{Variance decomposition}

Variance decomposition is a method to analyse the relative importance of every innovation to endogenous variables by decomposing the fluctuation and the reason of each variable in VAR/VEC model. Table 6 present the variance decomposition of LNBTC_SA, as the lag increase, the disturbance by itself decrease and impact from other variables increase. In lag period of $50,32.17 \%$ of impact is from USDI, $16.82 \%$ from DJIA, 10.54\% from FFR, 1\% from CPI and 0.25\% from GP.

\section{Analysis on the influence factors of Bitcoin's price}

From former study we tested out that the long run causality exists from CPI, DJIA, FFR, GP and USDI to BTC, the short run causality exists from CPI, GP and USID to BTC. Now we can analysis these influence factors individually based on results we have.

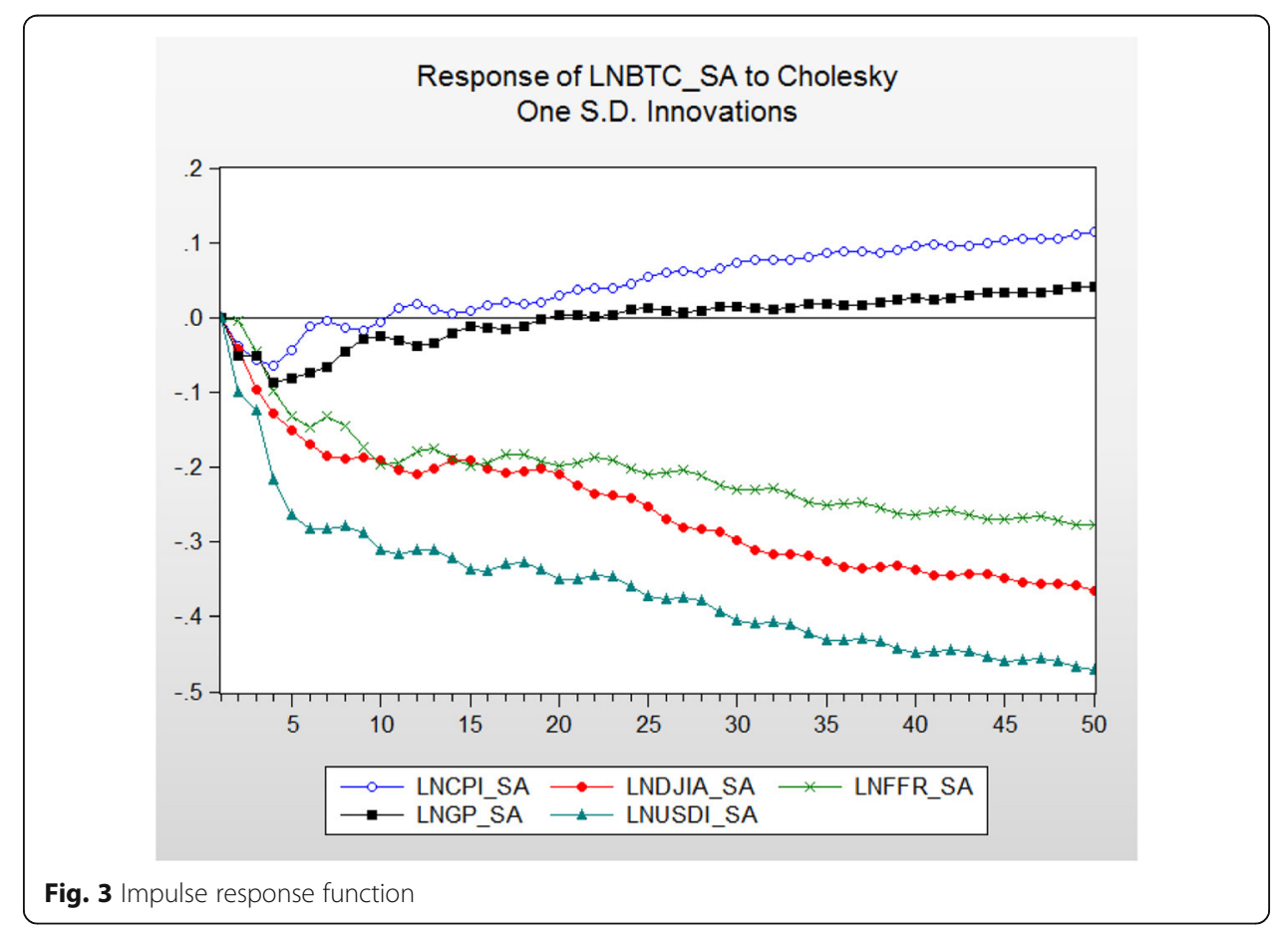


Table 5 Average impulse response to BTC in 50 period

\begin{tabular}{llllll}
\hline & LNCPI_SA & LNDJIA_SA & LNFFR_SA & LNGP_SA & LNUSDI_SA \\
\hline Average response & 0.04634724 & -0.25484298 & -0.20320814 & -0.00183942 & -0.35918224 \\
\hline
\end{tabular}

The relationship between BTC and CPI, BTC and USDI, BTC and DIA

We put these three group together because BTC and CPI, BTC and USDI, BTC and DJIA, they both have the same tendency, their trendlines lead to the same direction.

As present in figures, from September 2013 to January 2015, Bitcoin price experienced severe ups and downs, in the mean time, CPI, USDI and DJIA just smoothly go upwards in general.

From Bitcoin price's history, we can see clearly that Bitcoin price is mostly driven by events. In March 2013, Cyprus bank bail-in, the $€ 10$ billion bailout is hoped to fortify the flagging Cypriot economy. Seeking solutions to preserve their holdings before the bailout's conditions take effect, many of these account holders begin buying Bitcoin, brought the value of one Bitcoin from about $\$ 80$ to over $\$ 260$. In November 2013, both US government and Chinese government discussed about Bitcoin, both government stay positive towards Bitcoin's future. As a result, huge demand for Bitcoin arise, drive attention world widely to Bitcoin, push Bitcoin price once break \$1000 (this data did not show on our figures because we draw the figures using monthly average data), reach the highest level in Bitcoin price history. Bitcoin price rose 521\% in December 2013, for the first time bitcoin prices beyond 1 ounce of gold prices. The following notification "on the prevention of bit-currency risk notification" issued by The People's Bank of China and other five ministries on December $5^{\text {th }}$. This action means Chinese central bank banned financial institutions from using Bitcoin, and Third-party payment agencies stop to support the transfer and cash withdrawal of the Bitcoin trading platform. In February 2014, the world's largest Bitcoin Exchange platform Mt. Gox's website and trading engine go blank without official comment, on that day, Bitcoin prices plummeted 50\%. During the time Bitcoin price experiencing a dramatic change while CPI, USDI and DJIA did not change that much from March 2013 to February 2014. Presumably, the reason behind this can be, Bitcoin is similar to other financial assets traded on exchanges. Random event can cause a dramatically change on Bitcoin price in a shore period. The even can be government's attitudes; security incidents and other financial evens in the world.

Table 6 Variance decomposition of LNBTC_SA

\begin{tabular}{lllllll}
\hline Period & LNBTC_SA & LNCPI_SA & LNDJIA_SA & LNFFR_SA & LNGP_SA & LNUSDI_SA \\
\hline 1 & 100 & 0 & 0 & 0 & 0 & 0 \\
2 & 88.72089 & 1.051567 & 1.185032 & 0.016556 & 1.888619 & 7.137339 \\
3 & 82.06558 & 1.770305 & 4.011034 & 0.760684 & 1.931351 & 9.461043 \\
4 & 68.84896 & 2.067678 & 6.367946 & 2.701567 & 3.022276 & 16.99157 \\
5 & 58.68237 & 1.77231 & 8.255509 & 4.783119 & 3.215946 & 23.29074 \\
10 & 48.59186 & 0.60007 & 11.54285 & 8.228022 & 1.726649 & 29.31056 \\
20 & 44.88855 & 0.284278 & 12.25335 & 9.979117 & 0.732513 & 31.86219 \\
30 & 42.71013 & 0.476629 & 14.08435 & 10.04215 & 0.413245 & 32.2735 \\
40 & 40.51459 & 0.773933 & 15.87015 & 10.32418 & 0.279782 & 32.23737 \\
50 & 39.17296 & 1.035887 & 16.82198 & 10.54707 & 0.247408 & 32.1747 \\
\hline
\end{tabular}




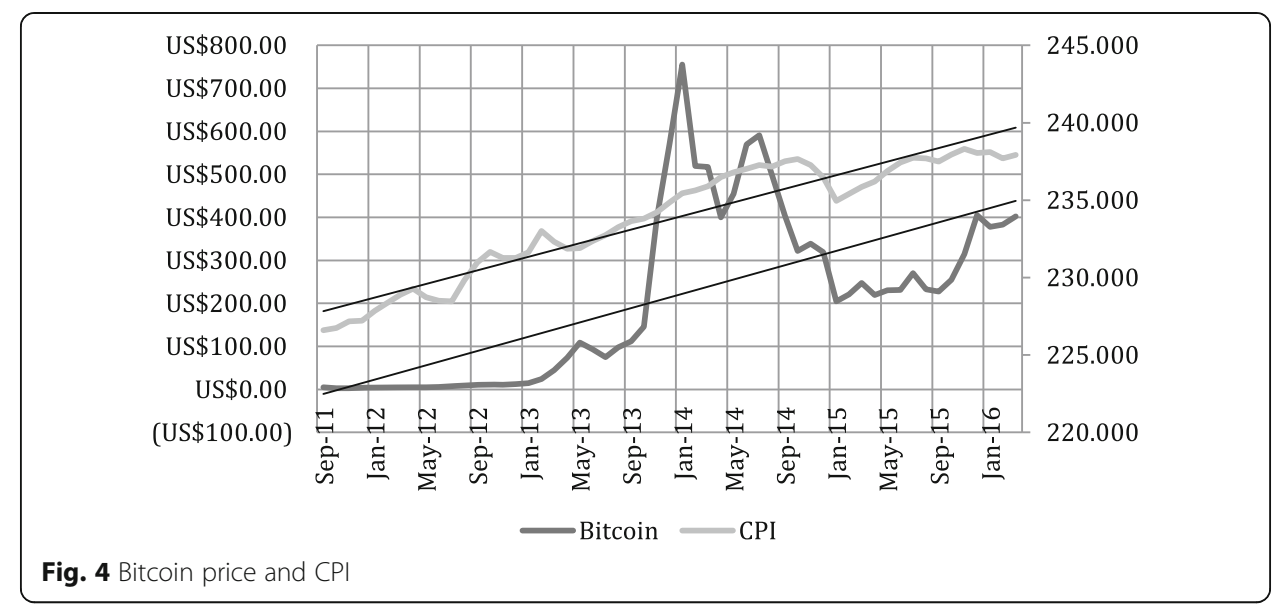

In addition to random events driven Bitcoin price change, macroeconomic indicators we analyzed still effect on Bitcoin price to some degree. In January 2015, as the price of gasoline fell, the CPI for the first time fell to a negative value in recent five years. As we can see in Fig. 4, Bitcoin price present the same curve during this period. Although we cannot attribute the fell of CPI to the fell of Bitcoin price, we can still see clearly that there is some connection in between.

Since July 2014, USDI rise by over 10\%, and October 29, 2014 the Federal Reserve decided to withdraw from the QE3. With the US economy recovery and the US dollar goes stronger, people's willingness to invest in other financial assets are weaken, Bitcoin price dropped significantly and in conjunction with gold price will talk about latter. Same observation appears on DJIA at the same period (Figs. 5 and 6).

From analysis above, we find out that, random event can cause a dramatically change on Bitcoin price in a short period. CPI, USDI and DJIA not only have a long term influence on Bitcoin price, they can also have a observable influence on Bitcoin price in short therm.

\section{The relationship between BTC and GP}

An overall decline began on gold price since the year 2013. From the beginning of 2013, gold ETF start a large-scale selling of gold assets, by the end of December 2013,

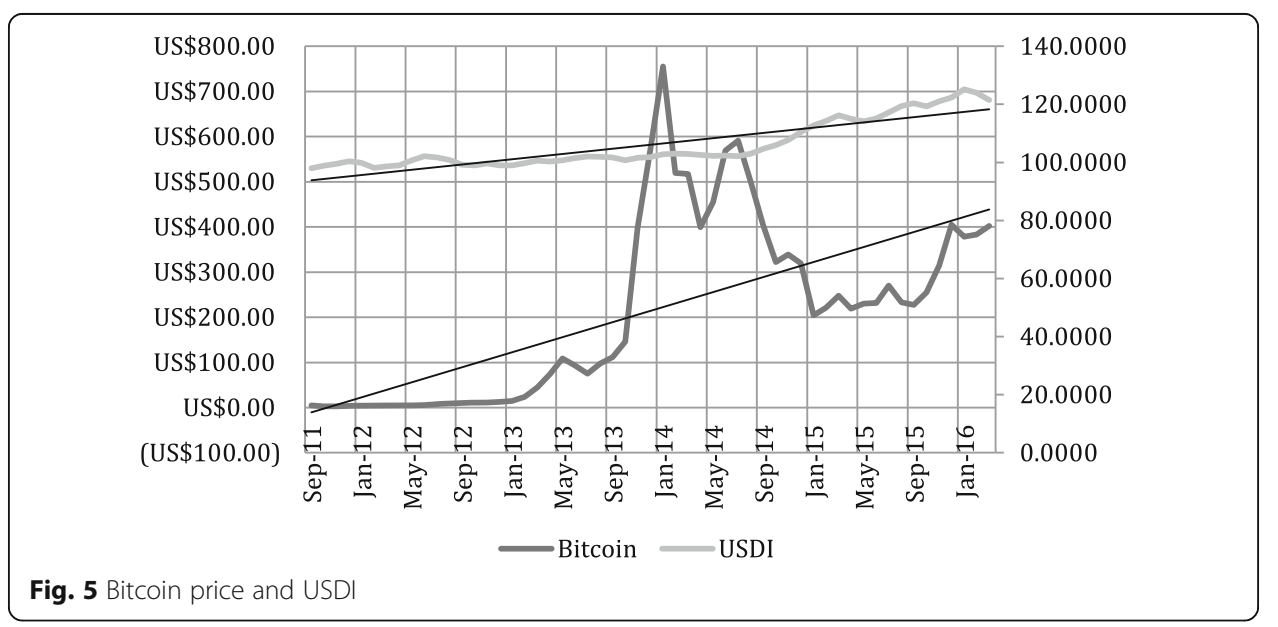




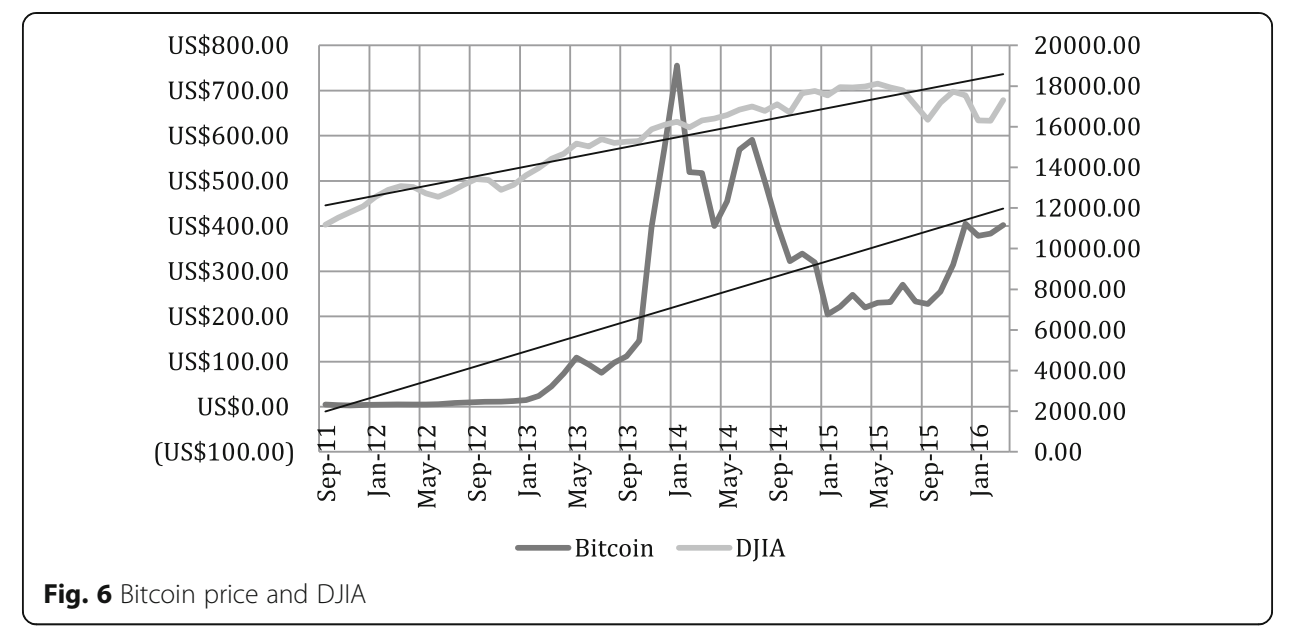

the position has been reduced by $40 \%$ and gold price fell all the way down. Other than ETF reduce gold's position, the Federal Reserve announced a \$ 10 billion reduction in bond purchases to response the QE Exit plan. This action leads to US dollar raise strongly, in conjunction with US stocks market's improving, all these factors cause international gold prices continue to weaken. To some extent, the reason why gold price fall down can also explain why Bitcoin price fall down. But, as present in Fig. 7, Bitcoin price and gold price have different variation tendencies, which means, they have the same trend in the short term and have different trend in the long term. To this point, we may treat Bitcoin as a hedge asset to gold in the long run.

\section{The relationship between BTC and FFR}

As an investment asset, the US Federal Reserve's Interest Rate Policy can have certain impact on Bitcoin price. In Fig. 8, we can clearly see a negative impact on Bitcoin price as FFR changes, when FFR goes down Bitcoin tend to goes up and vice versa. Increase in the FFR may have adverse impact on Bitcoin price based on the following two assumptions: rise in US dollar and reduce in speculative investments. First, the US dollar will benefit from the rate increase because raising interest rates may lead to

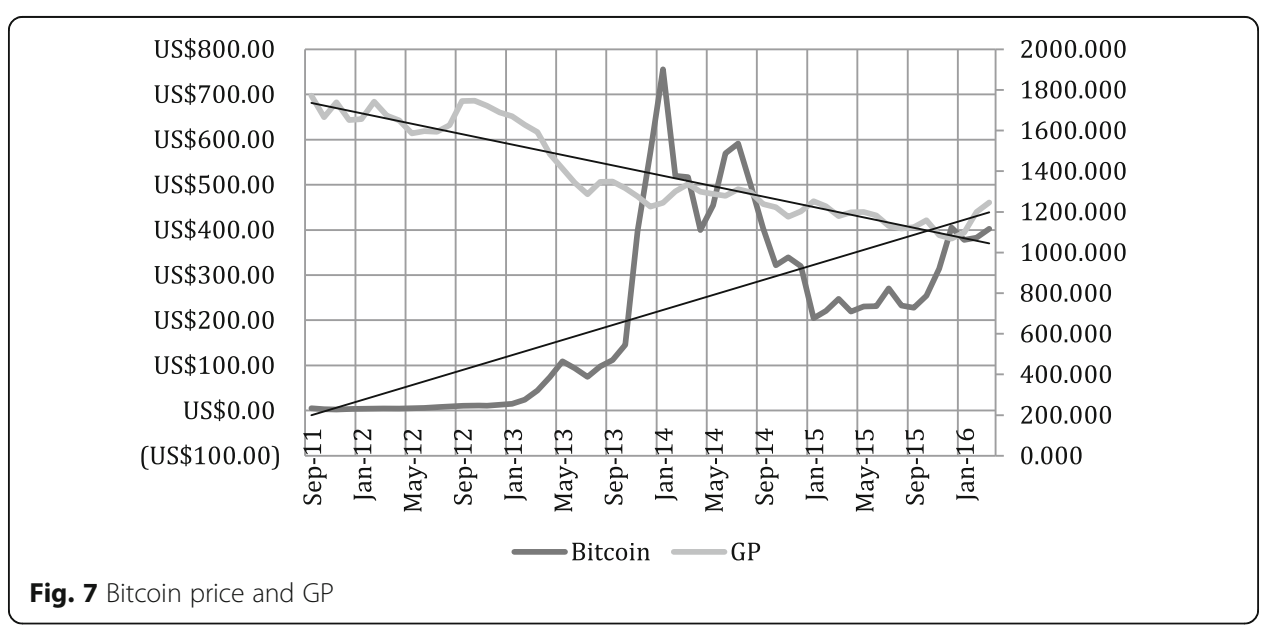




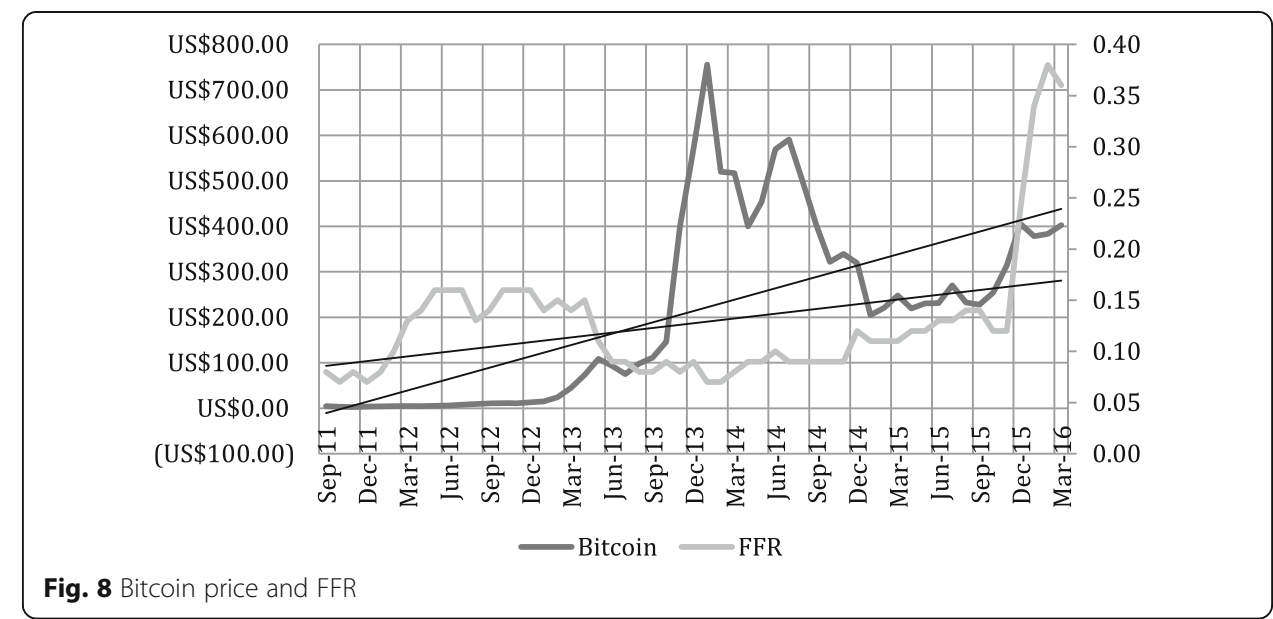

capital flow back to the US market therefore cause Bitcoin price fell. Second, increase in interest rate could reduce speculative investments. At this moment, Bitcoin is still a speculative asset; a large outflow to a more stable, lower risk areas of investment may have a negative impact on Bitcoin prices. Other than these two assumption, there are still a lot of complication relationship between Bitcoin price and FFR.

\section{Conclusions}

We analyzed the influence factors of Bitcoin's Price Based using VEC Model. The factors we chose are use gold price as an object of reference. From this point, we provided an analysis on the relationship between BTC and CPI, DJIA, FFR, USDI and GP. Empirical results suggest that economic factors such as CPI, DJIA, FFR and USDI do have a long-term negative influence on Bitcoin price. This result indicates that in the market Bitcoin behave similar to gold as a financial asset from a certain extend. But gold price has no influence on Bitcoin's price in the long run. The short run causality exists from CPI, GP, and USID to BTC. USDI is the strongest influence in all the variables we choose, the next to it is DJIA. This implies that to some extent, Bitcoin can be a hedge against US dollar or some other investment. However, GP surprisingly is barely a factor to influence Bitcoin price, so Bitcoin may not a hedge against the gold price.

What we did in this paper was consider Bitcoin more as an asset rather than a real currency. We can see from our result, Bitcoin price can be influenced under macroeconomic index and important assets price index, in other way we are saying Bitcoin is not only driven by it's own demand and supply. In a credit currency, the value can only driven by it's supply and demand, from this point of view, Bitcoin is now far from become a real currency.

In further study, we will focus on three points. First, we already identify the factors have influence on Bitcoin's price, next we will explore the mechanism of how these factors function on Bitcoin's price. Second, since $80 \%$ of Bitcoin transactions are from Chinese market, we attempt to use data only from Chinese market such as stock market index and Bitcoin trading frequency to analysis the relationship between Bitcoin's price and Chinese market. Finally, we will analysis digital currency from the perspective of monetary theory, define digital currency entirety to give suggestions on how can Bitcoin improve to make it's way as a real currency. 


\title{
Endnotes
}

\author{
${ }^{1}$ https://research.stlouisfed.org \\ ${ }^{2}$ http://bitcoincharts.com \\ ${ }^{3} \mathrm{R}$-square in lag $1=0.983746$, R-square in lag $4=0.992048$.
}

Funding

This work was supported by the Key Plan of National Social Science Foundation of China under the Grant 14ZDA044.

\section{Authors' contributions}

This paper is completed when YCZ study as visiting student in the University of Birmingham. YCZ collected the data and write the paper, DD who is my cooperate advisor, give the idea of the paper and JJL proposed the amendments to the paper and he is my Ph.D advisor. All authors read and approved the final manuscript.

\section{Competing interests}

The authors declare that they have no competing interests.

\section{Publisher's Note}

Springer Nature remains neutral with regard to jurisdictional claims in published maps and institutional affiliations.

\section{Author details}

${ }^{1}$ School of Finance, Central University of Finance and Economics, Beijing 100081, China. ²Department of Economics, Birmingham Business School, University of Birmingham, Birmingham B15 2TT, UK.

Received: 15 December 2016 Accepted: 15 March 2017

Published online: 22 March 2017

\section{References}

Anwar S, Ghulam S, Zakir H (2011) Relationship between Financial Sector Development and Sustainable Economic Development: Time Series Analysis from Pakistan. International Journal of Economics and Finance, 3(1):262

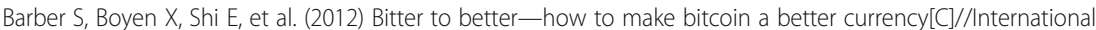
Conference on Financial Cryptography and Data Security. Springer Berlin Heidelberg, p 399-414 Bergstra J A, Weijland P (2014) Bitcoin: a Money-like Informational Commodity[J]. Eprint Arxiv

Cheah ET, Fry J (2015) Speculative bubbles in Bitcoin markets? An empirical investigation into the fundamental value of Bitcoin. Econ Lett 130:32-36

Cusumano MA (2014) The Bitcoin ecosystem. Commun ACM 57(10):22-24

Dyhrberg AH (2015) Bitcoin, gold and the dollar-A GARCH volatility analysis. Finance Res Lett

Dyhrberg AH (2015b) Hedging capabilities of bitcoin. Is it the virtual gold? Finance Res Lett 16:139-144

Dyhrberg AH (2016) Bitcoin, gold and the dollar - A GARCH volatility analysis. Finance Res Lett 16:85-92

Grinberg RB (2011) Bitcoin: An Innovative Alternative Digital Currency. Hastings Science \& Technology Law Journal, Vol. 4, p 160. Available at SSRN: https://ssrn.com/abstract=1817857

Herrerias MJ (2010) The causal relationship between equipment investment and infrastructures on economic growth in China[J]. Frontiers of Economics in China, 5(4):509-526

Ho SY, Odhiambo NM. (2013) Banking sector development and economic growth in Hong Kong: an empirical investigation [J]. The International Business \& Economics Research Journal (Online), 12(5):519

Jia L (2013) Bitcoin: theory, practice and influences. Stud Int Financ 12:14-25

Krugman P. (2011) Golden cyberfetters [J]. The New York Times, 7

Lawrence C (2003) Why is gold different from other assets? An empirical investigation [J]. London

Nakamoto S (2008) Bitcoin: a peer-to-peer electronic cash system

Sims CA (1980) Macroeconomics and reality. Econometrica 1-48

Smith G (2001) The price of gold and stock price indices for the United States. The World Gold Council 8:1-16

Šurda P, The Origin, Classification and Utility of Bitcoin (May 14, 2014). Available at SSRN: https://ssrn.com/abstract= 2436823 or http://dx.doi.org/10.2139/ssrn.2436823

World Gold Council (2002) Managing portfolio risk with gold., http://www.gold.org

Wu C, Pandey V (2014) The value of Bitcoin in enhancing the efficiency of an investor's portfolio. J Financ Plann 27:44-52

Yelowitz A, Wilson M (2015) Characteristics of Bitcoin users: an analysis of Google search data. Appl Econ Lett 22(13): 1030-1036

Yermack D (2013) Is Bitcoin a real currency? An economic appraisal. Natl Bur Econ Res 